STUDI

FRANCESI

\section{Studi Francesi}

Rivista quadrimestrale fondata da Franco Simone

168 (LVI | III) | 2012

Varia

\title{
Clotilde Thouret, Seul en scène. Le monologue dans le théâtre européen de la première modernité (1580-1640)
}

\section{Monica Pavesio}

\section{(2) OpenEdition}

1 Journals

\section{Edizione digitale}

URL: http://journals.openedition.org/studifrancesi/3714

DOI: 10.4000/studifrancesi.3714

ISSN: 2421-5856

\section{Editore}

Rosenberg \& Sellier

\section{Edizione cartacea}

Data di pubblicazione: 1 décembre 2012

Paginazione: 560-561

ISSN: 0039-2944

\section{Notizia bibliografica digitale}

Monica Pavesio, «Clotilde Thouret, Seul en scène. Le monologue dans le théâtre européen de la première modernité (1580-1640)», Studi Francesi [Online], 168 (LVI | III) | 2012, online dal 30 novembre 2015, consultato il 07 mars 2021. URL: http://journals.openedition.org/studifrancesi/3714 ; DOI: https:// doi.org/10.4000/studifrancesi.3714

Questo documento è stato generato automaticamente il 7 mars 2021.

\section{(c) $(1) \odot$}

Studi Francesi è distribuita con Licenza Creative Commons Attribuzione - Non commerciale - Non opere derivate 4.0 Internazionale. 


\title{
Clotilde Thouret, Seul en scène. Le monologue dans le théâtre européen de la première modernité (1580-1640)
}

\author{
Monica Pavesio
}

\section{NOTIZIA}

CLOTILDE THOURET, Seul en scène. Le monologue dans le théâtre européen de la première modernité (1580-1640), Genève, Droz, 2010, pp. 429.

1 Il libro di Clotilde Thouret si propone di ricostruire le ragioni poetiche, storiche ed antropologiche del monologo teatrale nell'Europa della prima modernità.

2 La prima parte, appoggiandosi sulle pratiche drammatiche dell'epoca, arriva alla ricostruzione di una poetica barocca del monologo. È in questo periodo che il monologo si afferma come una forma teatrale drammatica specifica. Le riflessioni dei teorici e le didascalie, che segnalano la sua differenza con il dialogo, lo definiscono come una nuova convenzione enunciativa teatrale. In questo primo periodo, - siamo intorno alla metà del Cinquecento - come ci illustra l'autrice, i teorici che si preoccupano di dare uno statuto alla nuova forma del monologo, sono soprattutto italiani: Giraldi Cinzio, Leone de' Sommi, Giovanni Battista Pigna. In Inghilterra e in Spagna, la forma del monologo non è oggetto di riflessione teorica; in Francia lo sarà solo più tardi. L'autrice specifica che la riflessione sul monologo non può fare a meno delle riflessioni teoriche degli Italiani e dei loro testi fondatori nel campo della teoria drammatica.

Dopo queste importanti premesse, stupisce e sconcerta la scelta dell'autrice di non inserire le opere teatrali italiane nel corpus del suo lavoro. È vero che si tratta di un corpus molto vasto, che comprende le opere di Shakespeare e dei drammaturghi inglesi del primo Seicento, un gran numero di comedias del Siglo de Oro e di opere drammatiche francesi secentesche, ma l'assenza totale della drammaturgia italiana ci sembra amputare l'interessante lavoro della Thouret di una voce essenziale. Non ci 
sembrano soddisfacenti le giustificazioni che l'autrice adduce per spiegare l'assenza dei corpus drammatico italiano, che avrebbe potuto completare il panorama europeo: l'aggiunta di altre opere avrebbe reso meno efficaci le analisi dettagliate dei monologhi; l'inclusione dell'Italia avrebbe portato al necessario allungamento del periodo preso in esame (perché il teatro italiano si sviluppa a partire dal primo Cinquecento); l'aggiunta dei monologhi italiani avrebbe impedito una comparazione rigorosa, resa possibile invece dall'evoluzione drammaturgica parallela dei teatri inglese, francese e spagnolo. Ci pare impossibile infatti analizzare la pratica del monologo nel teatro europeo nella prima modernità, senza prendere in considerazione il teatro italiano, che come si sa, ha avuto, tra l'altro, un'enorme influenza sul teatro francese secentesco.

4 Nonostante questo limite, il volume analizza la funzione scenica del monologo, quando nel corso del XVI e XVII secolo, con modalità proprie a ciascun paese, diventa il luogo dell'interiorità del personaggio ossia quando la rappresentazione dei pensieri e delle passioni danno forma a quel fenomeno antropologico di lunga durata che è l'interiorizzazione progressiva dell'identità. 